\title{
Aplikasi Pengenalan Budaya Jawa Tengah menggunakan Virtual Reality Berbasis Android
}

\author{
Rudolf Dekha Silaen ${ }^{1}$, Apri Junaidi $^{2}$, Ely Purnawati ${ }^{3}$ \\ S1 Teknik Informatika, Fakultas Informatika, Institut Teknologi Telkom Purwokerto \\ ${ }^{1} 16102031 @$ st3telkom.ac.id, ${ }^{2}$ apri@ittelkom-pwt.ac.id, ${ }^{3}$ elyhayyin@gmail.com
}

\begin{abstract}
At this time, it is very difficult to introduce culture to students in school, and this is also involved to children do not recognizing their own culture. Many schools have so limited funds to go to museums or cultural performances, especially school which are far from the capital city. Therefore, it is necessary to make an android-based application using Virtual Reality. This writing describes about a method of designing and making Central Javanese cultural learning-application for elementary and secondary school students by utilizing technological developments, one of the fields is education. In the field of education, Virtual Reality can be used as a learning media which is able to make it more attractive. This Virtual Reality technology can be applied in regional cultural learning systems, one of this is the introduction of Central Javanese culture. The use of Virtual Reality technology is expected to be able to display objects in the form of musical instruments, traditional clothes, traditional houses, paintings and traditional weapons in virtual 3D using images which can used to be markers. This making of cultural learning application using Unity, Blender, and SketchUp. The development of this application uses the waterfall model where this method pays close attention to the design of the analysis, design, implementation and testing. With this research, it is hoped that it can help students in Central Java to get to know their culture. This application is specified for students specifically for elementary and secondary schools based on Android. This application is expected to be used as an interactive alternative media besides books, so it's able to make students more interest on learning Central Javanese culture. This application will be made by using Unity and other assistive software and finally it will be refined with VR Box hardware to make it more real.
\end{abstract}

Keywords: Virtual Reality, Unity, Budaya, Blender, SketchUp, Waterfall.

\begin{abstract}
Abstrak
Pada saat ini, sulit sekali untuk mengenalkan budaya kepada anak-anak di sekolah-sekolah, dan ini juga mengakibatkan anak tidak mengenali budayanya sendiri. Banyak juga sekolah-sekolah yang terbatas akan dana untuk pergi ke museum atau tempat pengelaran budaya apalagi sekolah yang jauh dari kota. Oleh karena itu, maka diperlukan pembuatan aplikasi berbasis android menggunakan Virtual Reality. Penulisan ini menguraikan tentang metode perancangan dan pembuatan aplikasi pembelajaran budaya Jawa Tengah untuk anak sekolah dasar dan sekolah menengah dengan memanfaatkan perkembangan teknologi salah satunya bidang pendidikan. Pada bidang pendidikan Virtual Reality dapat digunakan sebagai media pembelajaran agar lebih menarik. Teknologi Virtual Reality ini dapat diterapkan dalam sistem pembelajaran budaya daerah salah satunya adalah pengenalan budaya Jawa Tengah. Penggunaan teknologi Virtual Reality diharapkan bisa menampilkan objek berupa alat musik, pakaian adat, rumah adat, lukisan dan senjata tradisional secara virtual 3D dengan menggunakan gambar yang dijadikan marker. Pembuatan aplikasi pembelajaran budaya ini dengan menggunakan Unity, Blender, dan SketchUp. Pengembangan aplikasi ini menggunakan model waterfall dimana metode ini memperhatikan dengan baik perancangan analisis, desain, implementasi dan uji coba. Dengan penelitian ini, diharapkan dapat membantu anak-anak yang ada di Jawa Tengah untuk mengenal budayanya. Aplikasi ini dispesifikan untuk anak sekolah yang spesifik untuk sekolah dasar dan sekolah menengah berbasis Android. Aplikasi ini diharapkan dapat digunakan sebagai media alternatif yang interaktif selain buku, sehingga menarik minat anak dalam mempelajari kebudayaan Jawa Tengah. Aplikasi ini akan dibuat dengan menggunakan Unity dan software bantu lainnya dan akhirnya akan disempurnakan dengan hardware VR Box agar lebih nyata.
\end{abstract}

Kata kunci: Virtual Reality, Unity, Budaya, Blender, SketchUp, Waterfall. 


\section{Rudolf Dekha Silaen ${ }^{1}$, Apri Junaidi ${ }^{2}$, Ely Purnawati ${ }^{3}$ \\ Journal of DINDA (Data Science, Information Technology, and Data Analytics) \\ Vol. 1 No. 2 (2021) $63-72$}

\section{Pendahuluan}

Budaya merupakan suatu cara hidup yang berkembang dan dimiliki bersama oleh sebuah kelompok orang dan diwariskan dari generasi ke generasi [12]. Budaya terbentuk dari banyak unsur yang rumit, termasuk Virtual Reality memungkinkan pengguna dan sistem agama dan politik, adat istiadat, bahasa, masyarakat untuk melihat dunia eksternal dengan perkakas, pakaian, bangunan, dan karya seni, dimensi berbeda. Teknologi ini dapat menghadirkan sebagaimana juga budaya, merupakan bagian tak sebuah dunia buatan dan mencoba hal yang tidak dapat terpisahkan dari diri manusia sehingga banyak orang diakses dalam kehidupan nyata dan menghadirkannya cenderung menganggapnya diwariskan secara genetis dalam pandangan pengguna. Gagasan awal dari Virtual [3].

Penyebab lunturnya budaya lokal terhadap generasi muda adalah kurangnya kesadaran masyarakat terhadap budaya lokal kini terbilang turun drastis, mereka lebih memilih budaya asing yang lebih praktis dan sesuai perkembangan zaman. Budaya asing mereka anggap dan perke lebih keren dan lebih praktis [13]. Jika terus seperti ini, dikembangkan seperti operasi pesawat, tank, sistem bukan tidak mungkin masyarakat akan kehilangan pembangkit listrik, dan pembedahan manusia [1]. kebudayaan dan tradisi Jawa. Budaya yang telah lama Banyaknya inovasi terjadi karena kekuatan Virtual melekat pada kepercayaan ini bisa saja punah kelak. Reality dalam meyakinkan pengguna dan meyakinkan Generasi muda yang kini lebih berpikir realistis dan kehadiran mereka di dalam lingkungan buatan. Virtual tidak percaya kepada hal-hal yang mistis dan lebih Reality juga menawarkan lingkungan interaktif yang senang pada gaya hidup modern. Akan lebih baik jika melibatkan peserta didik dan memungkinkan mereka memahami segala budaya yang diwariskan nenek memvisualisasikannya. Teknologi ini diperkenalkan moyang agar dapat menyaring kebudayaan asing yang sebagai alat inovasi untuk memecahkan masalah semakin menjarah perilaku [11].

Yang melatarbelakangi peneliti mengambil penelitian ini, peneliti ingin melestarikan budaya Jawa Tengah di

era modern ini agar budaya Jawa tersebut dapat tetap Aplikasi Android menjadi salah satu sistem aplikasi dilestarikan di Indonesia. Dari beberapa artikel yang yang paling banyak digunakan di dunia saat ini, peneliti dibaca, ada beberapa media yang mengangkat perlu mengharapkan aplikasi ini dapat membantu pengenalan budaya Jawa pada proses pembelajaran di pembelajaran kebudayaan untuk anak-anak sekolah sekolah dan juga dikarenakan kejayaan kehidupan khususnya, dan masyarakat umumnya untuk lebih kraton di masa lampau banyak terdapat di daerah Jawa mengenal macam-macam kebudayaan yang ada di Jawa Tengah dibandingkan di daerah Jawa yang lainnya Tengah melalui Virtual Reality berbasis Android [8]. [11]. Menurut media yang mengangkat, perlunya Berdasarkan permasalahan di atas, maka peneliti pengenalan budaya Jawa Tengah dikarenakan takut tertarik untuk membuat aplikasi pembelajaran budaya lunturnya budaya di Jawa sendiri seperti yang dilihat, khususnya daerah Jawa Tengah untuk anak sekolah tidak semua pemuda Jawa bisa berbahasa Jawa. yang spesifik untuk sekolah dasar dan sekolah Namun, satu hal yang dapat dibanggakan adalah menengah berbasis Android. Aplikasi ini diharapkan kebudayaan Jawa merupakan kebudayaan yang mampu dapat digunakan sebagai media alternatif yang mewarnai Kebudayaan Nasional. Pendidikan di sekolah interaktif selain buku dan internet, sehingga menarik merupakan sarana yang sangat penting untuk ikut minat anak dalam mempelajari kebudayaan Jawa meluruskan dan melestarikan kebudayaan Jawa [14]. Tengah. Aplikasi ini akan dibuat dengan menggunakan Dalam melakukan pengenalan budaya Jawa Tengah, Unity dan software bantu lainnya dan akhirnya akan harus lebih memperbanyak sumber untuk disempurnakan dengan hardware Virtual Box agar mendapatkannya dan tidak tergantung pada media yang

sudah ada dengan berbagai keterbatasannya, baik dalam $3 D$ Modelling dari suatu objek dapat dilihat sebagai penampilannya ataupun dalam ketergantungannya pada proses lengkap yang dimulai dari mendapatkan data sumber daya lainnya maka peneliti membuat inovasi dan berakhir dengan sebuah model 3D yang interaktif baru yang lebih menarik dan interaktif, yaitu: dengan dalam sebuah komputer. Kadang pemodelan 3D hanya menggunakan Virtual Reality untuk pengenalan budaya diartikan sebagai proses konversi sebuah ukuran yang Jawa Tengah, dengan menggunakan kacamata Virtual terbayang-bayang menjadi jaring-jaring yang Box agar pengguna seakan melihat secara objek yang berbentuk segitiga (mesh) atau permukaan yang ada di dalam rumah Joglo sehingga memberikan memiliki texture, walaupun hal tersebut harus

Journal of DINDA (Data Science, Information Technology, and Data Analytics)

Vol. 1 No. 2 (2021) $63-72$ 


\section{Rudolf Dekha Silaen ${ }^{1}$, Apri Junaidi ${ }^{2}$, Ely Purnawati ${ }^{3}$ \\ Journal of DINDA (Data Science, Information Technology, and Data Analytics) \\ Vol. 1 No. 2 (2021) $63-72$}

menggambarkan proses yang kompleks dari rekonstruksi sebuah objek [5].

Gambar 3. Kebudayaan [16]

Android adalah sebuah sistem operasi untuk perangkat mobile berbasis Linux yang mencakup sistem operasi, middleware dan aplikasi. Android menyediakan platform terbuka bagi para pengembang unuk menciptakan apikasi mereka [4].

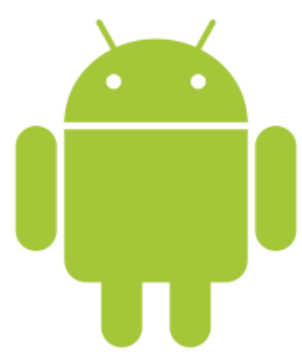

Gambar 1. Android [18]

Blender merupakan software animasi gratis dan open source $3 D$ creation suite. Blender mendukung berbagai macam fitur dari 3D modeling, rigging, animasi, simulasi, rendering, compositing dan motion tracking. Bahkan, Blender juga bisa digunakan untuk video editing dan dapat digunakan untuk membuat game.

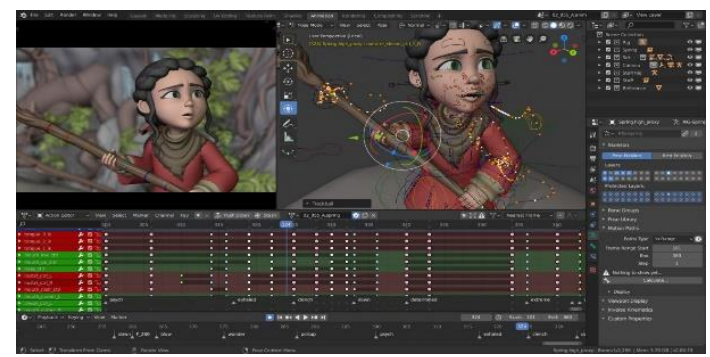

Gambar 2. Blender [17]

Menurut Andreas Eppink, kebudayaan mengandung keseluruhan pengertian nilai sosial, norma sosial, ilmu pengetahuan serta keseluruhan struktur-struktur sosial, religius, dan lain-lain, tambahan lagi segala pernyataan intelektual dan artistik yang menjadi ciri khas suatu masyarakat. Menurut Edward Burnett Tylor, kebudayaan merupakan keseluruhan yang kompleks, yang di dalamnya terkandung pengetahuan, kepercayaan, kesenian, moral, hukum, adat istiadat, dan kemampuan-kemampuan lain yang didapat seseorang sebagai anggota masyarakat [11].

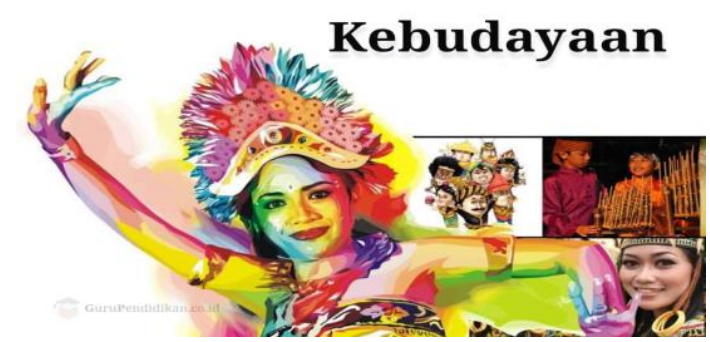

Journal of DINDA (Data Science, Information Technology, and Data Analytics)

Vol. 1 No. 2 (2021) $63-72$

Unity Engine merupakan suatu game engine yang terus berkembang, salah satu game engine dengan lisensi source proprietary, namun untuk lisensi pengembangan dibagi menjadi 2, yaitu: free (gratis) dan paid (berbayar) sesuai perangkat target pengembangan aplikasi [2]. Unity tidak membatasi publikasi aplikasi, pengguna unity dengan lisensi gratis dapat mempublikasikan aplikasi yang dibuat tanpa harus membayar biaya lisensi atau royalti kepada Unity. Tetapi penggunaan versi free dibatasi dengan beberapa fitur yang dikurangi atau bonus modul tertentu yang ditiadakan dan hanya tersedia untuk pengguna berbayar [9].

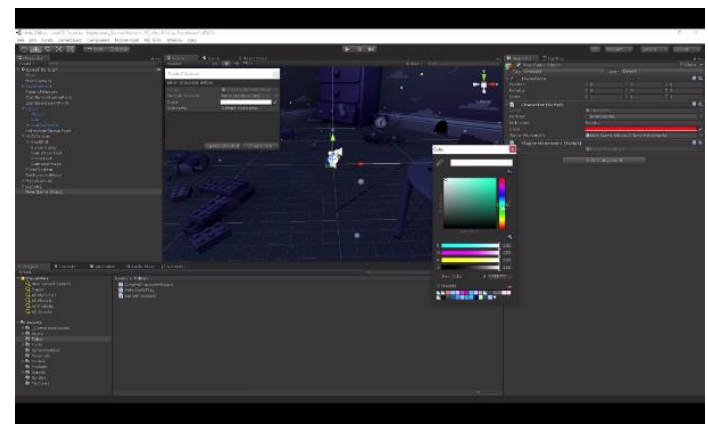

Gambar 4. Unity3D Engine [16]

SketchUp yaitu aplikasi berupa model 3D intuitif yang memungkinkan membuat dan mengedit model 2D dan 3D menggunakan teknik cara push-and-pull yang telah dipatenkan. Menggunakan perangkat push-and-pull, desainer dapat mengubah permukaan datar apa pun menjadi bentuk 3D [6]. Yang bisa Anda lakukan, yaitu: klik pada objek dan setelah itu seret sampai Anda menyukai apa yang Anda lihat. SketchUp merupakan program yang dipakai untuk berbagai proyek serta model 3D seperti arsitektur, desain interior, arsitektur lansekap, desain video game, dan desain yang berhubungan [15].

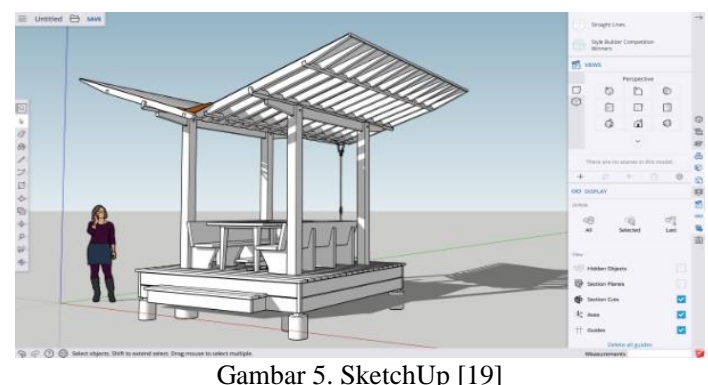

Virtual Environment (VE) atau Virtual Reality (VR) merupakan ruang digital dimana seluruh gerakan pengguna dapat diketahui atau dilacak dan mengetahui gambaran sekitarnya. Hasil yang didapat disusun dan ditampilkan ke indra manusia sesuai dengan gerakangerakan yang dilakukan. Augmented Reality (AR) 


\section{Rudolf Dekha Silaen ${ }^{1}$, Apri Junaidi ${ }^{2}$, Ely Purnawati ${ }^{3}$ \\ Journal of DINDA (Data Science, Information Technology, and Data Analytics) \\ Vol. 1 No. 2 (2021) $63-72$}

adalah suatu teknologi yang dapat menggambarkan dan menggabungkan dunia nyata dan dunia virtual yang dibuat melalui komputer sehingga batas antara keduanya menjadi sangat tipis. Augmented Reality (AR) adalah variasi dari Virtual Environment (VE) atau yang sering disebut Virtual Reality (VR). Augmented Reality dikenalkan pada tahun 1990 oleh Thomas Caudell, seorang karyawan perusahaan Boeing pada saat itu [15].

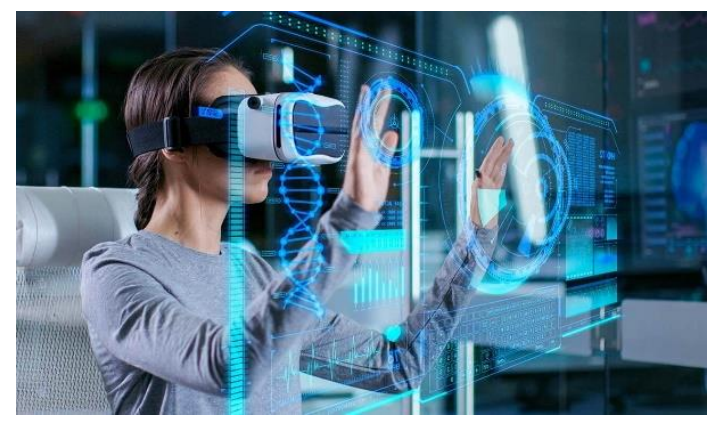

Gambar 6. Virtual Reality [20]

VR Box 3D Virtual Reality adalah semacam kacamata bentuknya kotak yang digunakan untuk memainkan game berformat 3D serta menikmati video atau film berformat 3D. Akan tetapi kacamata VR Box 3D Virtual Reality ini khusus digunakan untuk smartphone. Dan juga di Kacamata VR Box 3D Virtual Reality ada tali yang fungsinya untuk menyangga Kacamata VR Box 3D Virtual Reality tersebut agar tidak jatuh [10].

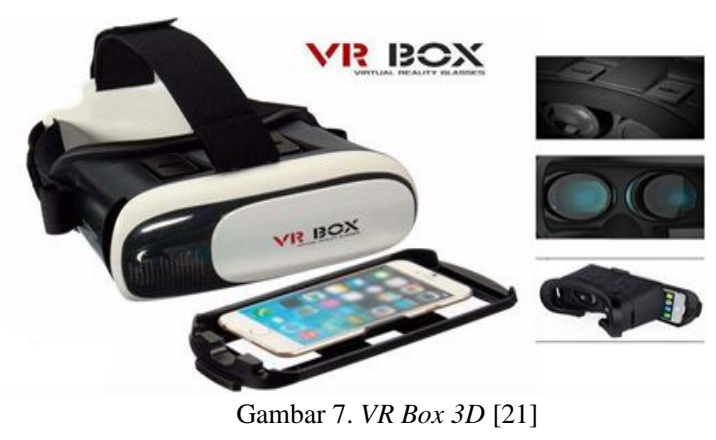

Virtual Reality dapat menjadi salah satu alternatif yang dapat diimplementasikan untuk suatu media pembelajaran bagi semua kalangan dan juga peserta didik mulai dari usia muda hingga siswa sekolah menengah atas, dikarenakan medianya yang lebih interaktif dan tidak mudah membuat bosan.

Tujuan dari penelitian ini adalah pembuatan aplikasi pengenalan budaya Jawa Tenagh menggunakan Virtual Reality berbasis Andorid yang digunakan untuk mengenalkan budaya Jawa Tengah bagi masyarakat dan generasi muda yang terdapat objek budaya Jawa Tengah berupa rumah adat, alat musik, pakaian adat, senjata tradisional, dan lukisan.

\section{Metode Penelitian}

Tahapan penelitian dalam perancangan aplikasi pengenalan budaya Jawa Tengah menggunakan Virtual Reality berbasis Android beserta fungsinya dengan berbasis web menggunakan model waterfall. Tahapantahapan penelitian tersebut disusun secara sistematis dengan tujuan agar mempermudah peneliti dalam melakukan pengembangan sistem.

\subsection{Metode Waterfall}

Metode waterfall merupakan pendekatan perangkat lunak yang sistematik dan sekuensial yang dimulai dari tahap analisis, desain, kode, pengujian dan pemeliharaan. Model waterfall ljuga dikenal sebagai linier sequential atas. Model waterfall pada penelitian ini melingkupi aktivitas-aktivitas secara garis besar seperti:

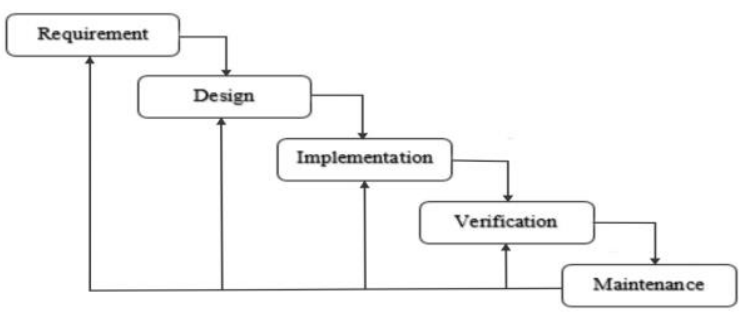

Gambar 8. Model Waterfall

\subsection{Requirement}

Requirement dilakukan proses yang meliputi seluruh kebutuhan sistem yang diperlukan, meliputi kegunaan dari software atau sistem yang akan dibuat dan batasan batasannya. Informasi analisis sistem dapat diperoleh melalui jurnal, wawancara survei atau diskusi dengan para ahli tentang kebutuhan software yang sekiranya diperlukan nantinya. Peneliti juga mencari data dan mengumpulkan data tentang budaya yang ada di Jawa Tengah berupa objek pakaian adat, senjata tradisional, alat musik dan lukisan yang data tersebut valid dan bisa dijadikan objek untuk pembuatan aplikasi tersebut.

\subsection{Desain}

Dalam tahap ini, penulis akan melakukan perancangan tampilan dari aplikasi yang akan dibuat. Dalam merancang aplikasi ini, penulis menggunakan use-case diagram untuk menggambarkan aktivitas apa saja yang dapat dilakukan oleh sistem. Selain itu, struktur navigasi dan storyboard juga digunakan untuk membuat alur dari aplikasi agar dapat mempermudah dalam pembuatan aplikasi. 


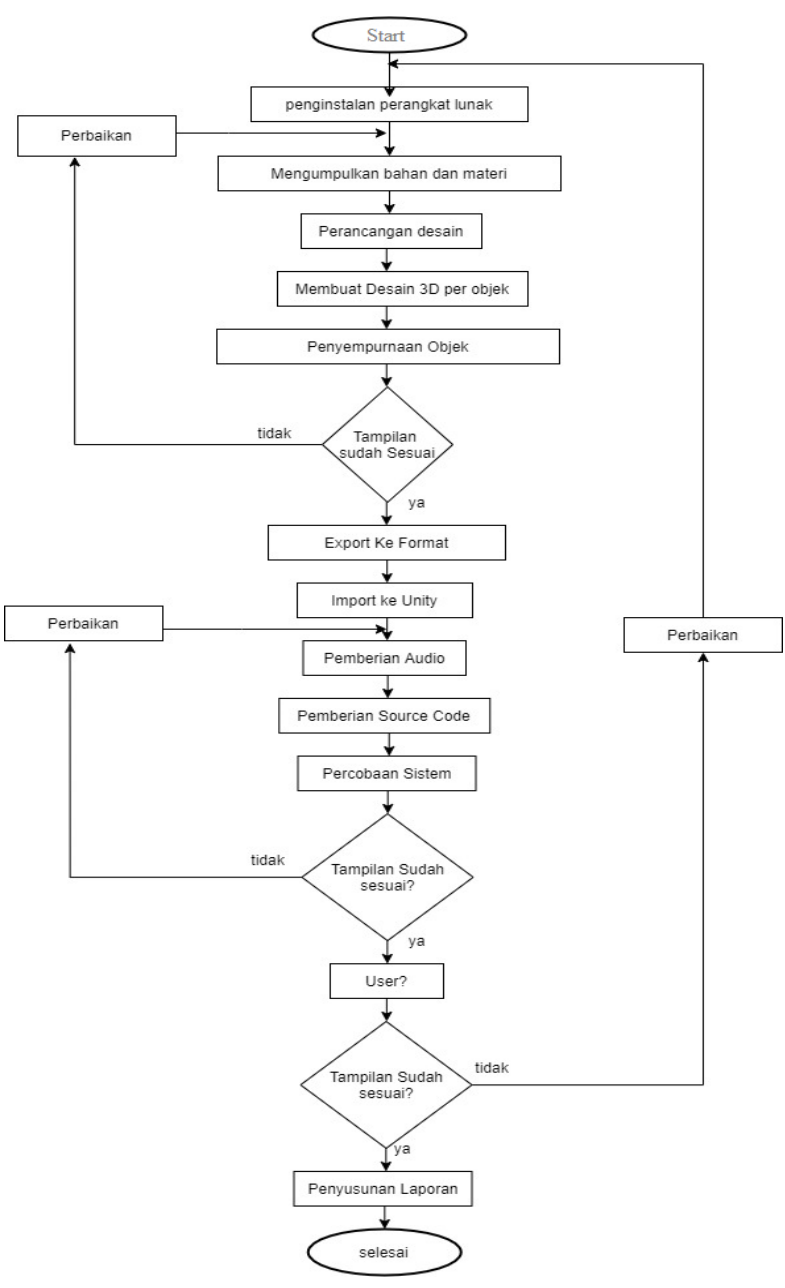

Gambar 9. Alur Penelitian

Use Case merepresentasikan sebuah interaksi antara actor/user dengan sistem dan menggambarkan fungsionalitas yang diharapkan dari sebuah sistem. Diagram pada gambar use case terdiri dari 1 aktor dan 8 use case. Di dalam diagram ini terdapat beberapa extend yang digunakan untuk menunjukkan bahwa satu use case merupakan tambahan fungsional dari use case lain jika kondisi tertentu terpenuhi.

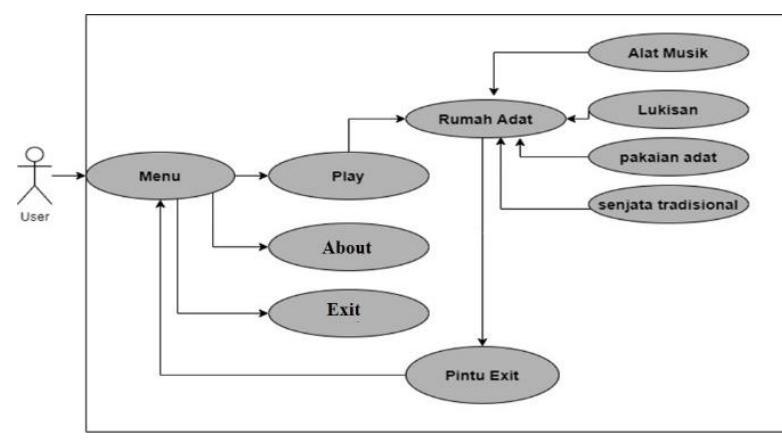

Gambar 10. Use Case Diagram

Pentingnya desain user interface pada pembuatan aplikasi berpengaruh besar atas keberhasilan aplikasi tersebut. Desain pada user interface ini merupakan gambaran dasar pada aplikasi pengenalan budaya Jawa Tengah. Pada gambar di bawah ini merupakan desain kasar pada aplikasi Pengenalan budaya Jawa Tengah untuk halaman awal saat memasukkan aplikasi pengenalan budaya Jawa Tengah.

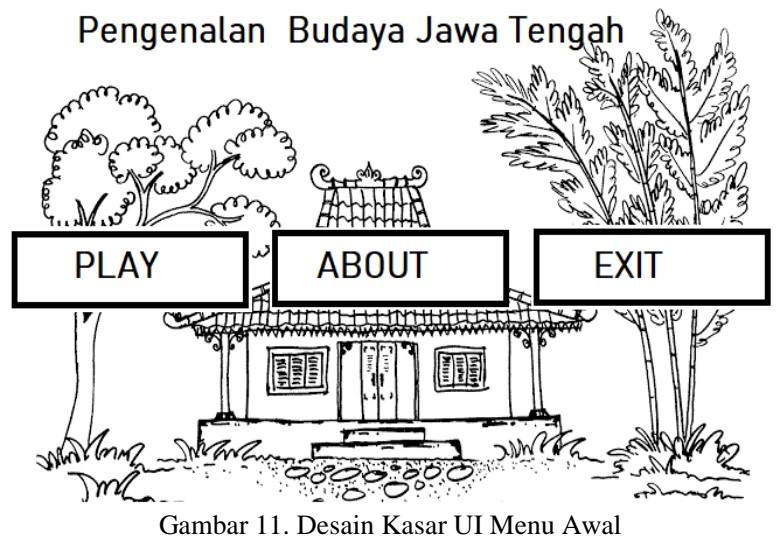

Saat user memilih tombol play, maka user akan langsung masuk ke dalam halaman depan rumah Joglo. Kemudia user harus masuk ke dalam pintu untuk menikmati objek-objek budaya pada rumah Joglo tersebut. Pada halaman rumah Joglo juga ada pintu keluar untuk user kembali ke halaman awal.

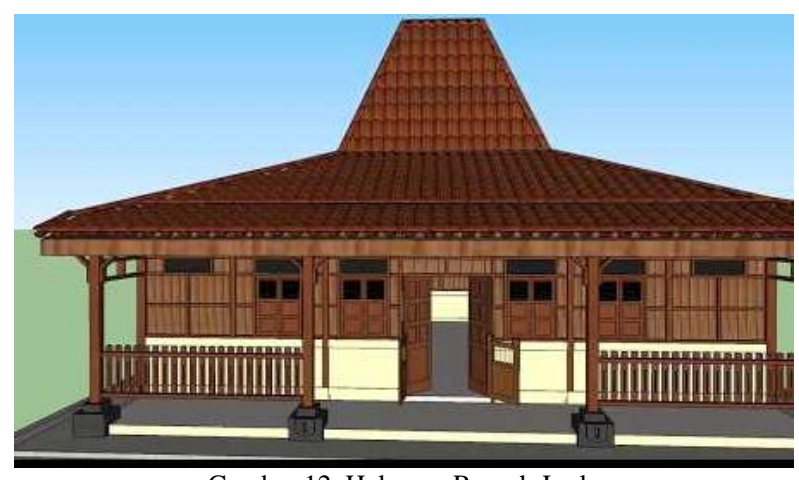

Gambar 12. Halaman Rumah Joglo

\subsection{Implementation}

Tahap implementasi ini adalah tahap di mana penulis membuat atau mengerjakan desain yang telah di buat pada aplikasi Blender dan SketchUp dan akan diimport-kan ke dalam Unity. Setelah itu, objek yang telah di-import akan digabungkan dan dijadikan aplikasi yang telah direncanakan dan dirancang dengan menggunakan software Unity.

\subsection{Verification}

Pada tahap pengujian dilakukan verifikasi dan validasi pada aplikasi perangkat lunak dan diambil kesimpulan dari proses testing tersebut. Tahap pengujian digunakan untuk menentukan kesalahan atau debug pada saat pembuatan aplikasi. Pada tahapan pengujian ini menggunakan white box dan black box testing dimana white box nantinya akan berfokus mengecek kompleksitas dari suatu source code sesuai dengan

Journal of DINDA (Data Science, Information Technology, and Data Analytics) Vol. 1 No. 2 (2021) $63-72$ 


\section{Rudolf Dekha Silaen ${ }^{1}$, Apri Junaidi ${ }^{2}$, Ely Purnawati ${ }^{3}$ \\ Journal of DINDA (Data Science, Information Technology, and Data Analytics) \\ Vol. 1 No. 2 (2021) $63-72$}

kebutuhan fungsionalnya sedangkan black box akan menghasilkan output pengujian yang dilakukan oleh pengguna.

\subsection{Maintenance}

Ini merupakan tahapan terakhir dari model waterfall. mengarahkan reticle / white dot (berdasarkan gerakan Software yang dibangun sudah selesai dan dapat kepala) ke salah satu menu yang akan dipilih. digunakan selanjutnya memasuki tahapan pemeliharaan sistem. Pemeliharaan sistem penting dilakukan karena software tersebut mempunyai kemungkinan adanya error atau bug setelah digunakan dalam kurun waktu tertentu. Dan juga pemeliharaan dibutuhkan karena aplikasi memungkinkan adanya tambahan fitur yang akan di-update seiring berjalannya waktu oleh pembuat atau developer dari aplikasi tersebut.

\subsection{Tabel}

Tabel harus diberi nomor sesuai urutan presentasi (Tabel 1, dst.). Judul tabel ditulis diatas tabel dengan posisi rata tengah (center justified), tidak ada cetak tebal maupun berwarna. Font yang dipakai berukuran 8 pt baik judul tabel maupun isi tabel. Tabel harus diacu dan dirujuk dalam text.

Tabel 1.Tabel Software dan Hardware Pendukung

\begin{tabular}{lll}
\hline Product & Server & Client \\
\hline Clementine & Solaris 2.X & X Windows \\
Darwin & Solaris 2.X & Windows NT \\
PRW & Data on & Windows NT \\
\hline
\end{tabular}

\subsection{Gambar}

Gambar diberi nomor sesuai urutan presentasi (Gambar.1, dst.). Judul gambar diletakkan dibawah gambar dengan posisi tengah (centre justified). Font yang dipakai dalam judul gambar berukuran 8pt. Gambar harus diacu dan dirujuk dalam text.

\section{Hasil dan Pembahasan}

\subsection{Hasil Implementasi}

Aplikasi pengenalan budaya Jawa Tengah menggunakan Virtual Reality berbasis Android dan dapat berjalan pada sistem operasi android minimal versi Android 4.4 KitKat (API 19). Untuk menjalankan aplikasi ini, ada ketentuan-ketentuan pada perangkat smartphone ini adalah mendukung sensor gyroscope, google cardboard, dan satu set VR Box.

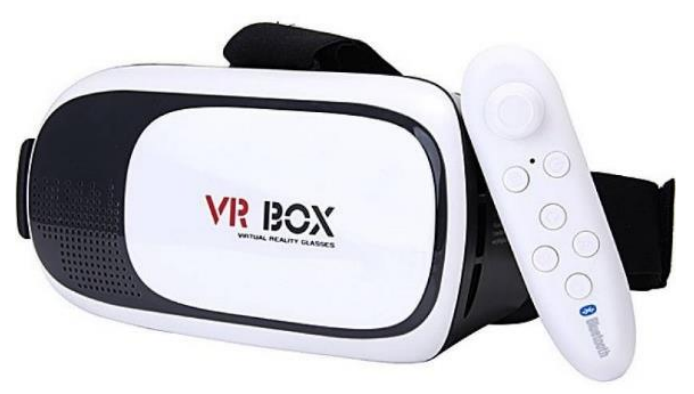

Gambar 13. VR Box dan Controller

Journal of DINDA (Data Science, Information Technology, and Data Analytics)

Vol. 1 No. 2 (2021) $63-72$
Menu utama merupakan menu yang berisi beberapa pilihan menu yang dapat dipilih oleh pengguna (user). Menu utama ini memiliki 3 pilihan, yaitu: play, about, exit. Untuk memilih salah satu menu, pengguna dapat Berikut adalah hasil implementasi dari rancangan aplikasi untuk tampilan interface menu utama dapat dilihat pada gambar di bawah ini.

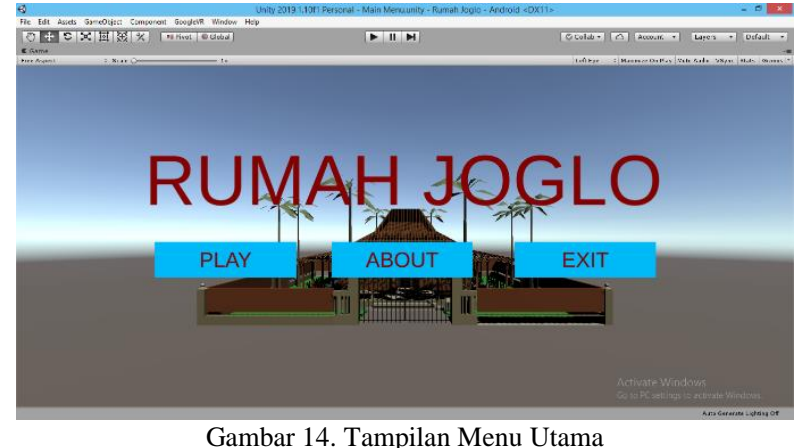

About berisi penjelasan cara menggunakan aplikasi Virtual Reality "Rumah Joglo" beserta biografi singkat tentang penulis, dapat dilihat pada gambar di bawah ini.

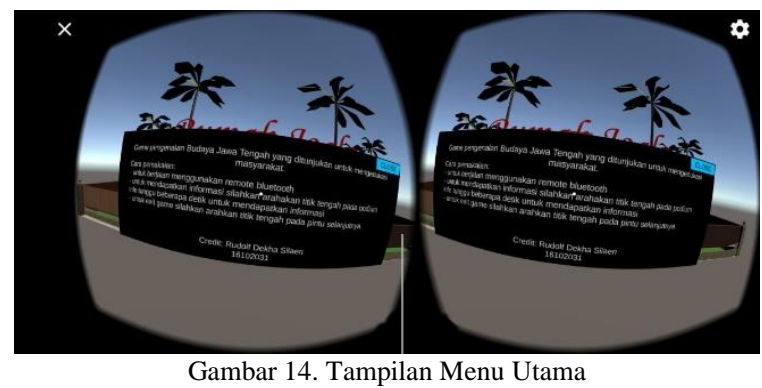

Di dalam scene ini dimulai terdapat sebuah reticle / white dot sebagai titik tengah pandangan pengguna (user) berfungsi untuk meng-klik pada suatu objek agar dapat muncul papan informasi pada objek tersebut. Pengguna dapat berjalan sesuai tombol controller pada VR Box.

Berikut adalah hasil implementasi dari rancangan aplikasi untuk tampilan interface rumah Jolgo dapat dilihat pada gambar di bawah ini.

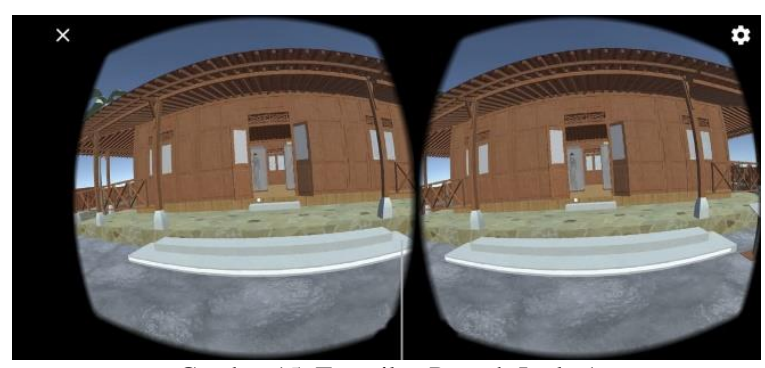

Gambar 15. Tampilan Rumah Joglo 1 


\section{Rudolf Dekha Silaen ${ }^{1}$, Apri Junaidi ${ }^{2}$, Ely Purnawati ${ }^{3}$ \\ Journal of DINDA (Data Science, Information Technology, and Data Analytics) \\ Vol. 1 No. 2 (2021) $63-72$}

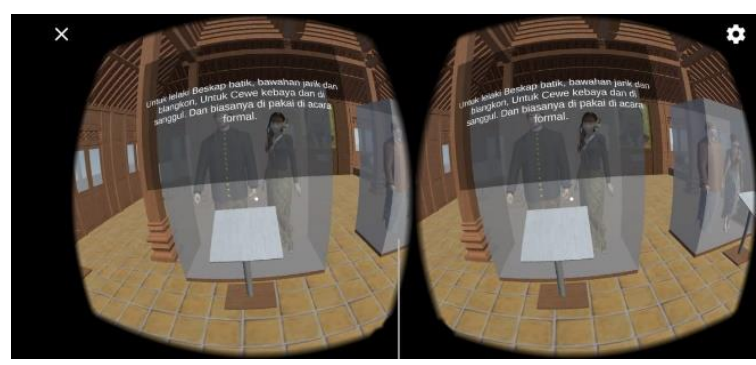

Gambar 16. Tampilan Rumah Joglo 2

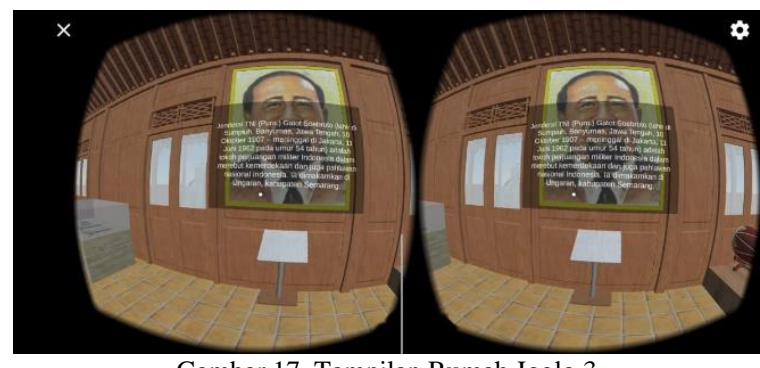

Gambar 17. Tampilan Rumah Joglo 3

\subsection{Hasil Pengujian dan Analisis}

Pengujian dilakukan dengan memberikan pembelajaran data kuesioner yang telah diisi dan selanjutnya akan kepada responden berdomisili di Jawa Tengah dan diolah menjadi kesimpulan dari responden. Skala yang berkuliah di Institut Teknologi Telkom Purwokerto. diberikan dari 0 sampai 10 dan rumus untuk Sebelum melakukan pembelajaran, penulis berdiskusi menghitung rata-rata, sebagai berikut: dengan responden untuk menentukan tempat (aplikasi) dan waktu untuk melakukan pembelajaran. Setelah itu, penulis akan mengirimkan link dimana dapat bergabung dengan aplikasi Google Meeting di WhatsApp. Jadi, jumlah responden telah bergabung sebanyak 33 orang. Alat-alat yang digunakan dalam memberikan pembelajaran berupa satu buah laptop, satu buah smartphone, dan satu buah VR Box.

Pada saat pelaksanaan menggunakan video demo aplikasi Virtual Reality "Rumah Joglo", penulis akan menjelaskan cara pemakaian melalui video demo tersebut. Setelah selesai pembelajaran, setiap responden akan diberikan kuesioner tentang aplikasi Virtual Reality "Rumah Joglo". Beberapa foto pada saat waktu pelaksanaaan pembelajaran yang dilakukan dapat dilihat pada gambar di bawah ini.

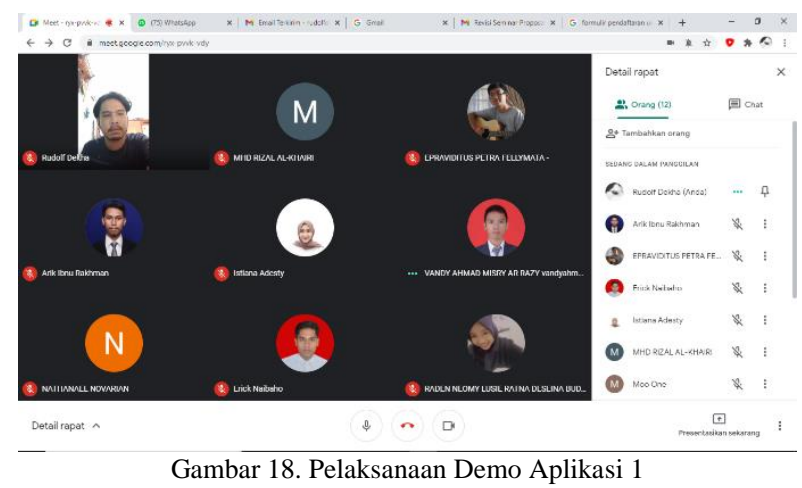

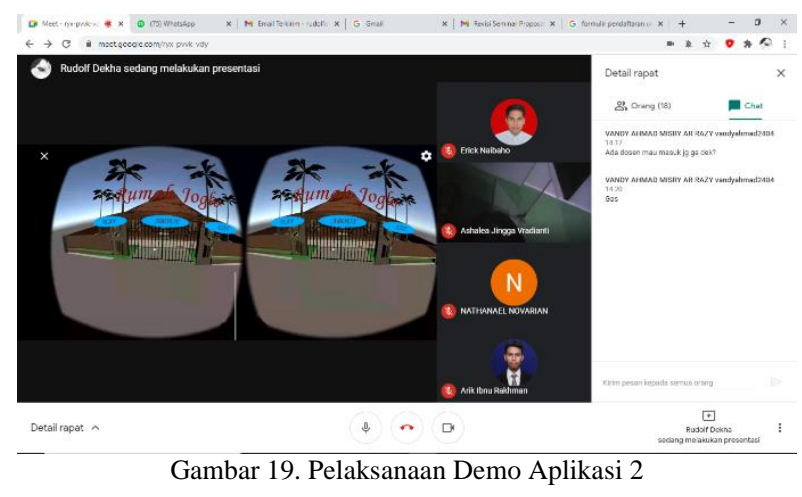

3.3. Evaluasi

Evaluasi dilakukan setelah mendapatkan data dari kuesioner yang digunakan untuk mengetahui testimoni responden terhadap aplikasi. Kemudian, secara keseluruhan dapat disimpulkan bahwa ini menjadi kelebihan dan kekurangan yang ada pada aplikasi Virtual Reality "Rumah Joglo" tersebut.

Analisis responden diperlukan untuk mengetahui kelebihan dan kekurangan pada aplikasi tersebut berdasarkan tanggapan terhadap kuesioner yang telah diisi oleh responden. Data yang diperoleh dari hasil Rata - rata $=\frac{\text { total nilai jawaban }}{\text { total nilai maksimal }}$

Berikut adalah data kuesioner dengan responden dapat dilihat pada Tabel, sebagai berikut:

Tabel 1. Daftar Nama Responden

\begin{tabular}{clc}
\hline No. & \multicolumn{1}{c}{ Nama } & Kode \\
\hline 1 & Vandy Ahmad Misry Ar Razy & R1 \\
2 & Wiwit Farianto & R2 \\
3 & Raden Neomy L R D B P & R3 \\
4 & Ashalea Jingga & R4 \\
5 & Maseen & R5 \\
6 & Reno Agil Saputra & R6 \\
7 & Dimas Damar Galih & R7 \\
8 & Johanes Halomoan Lubis & R8 \\
9 & Nathanael Novarian & R9 \\
10 & Erick Sebastian Naibaho & $\mathrm{R} 10$ \\
11 & Boma Bayu & $\mathrm{R} 11$ \\
12 & Arik Ibnu Rakhman & $\mathrm{R} 12$ \\
13 & Sapayo & $\mathrm{R} 13$ \\
14 & Ika Rahmawati Suci & $\mathrm{R} 14$ \\
15 & Dendy Ramdani & $\mathrm{R} 15$ \\
16 & Alfira Mahda Ramadini & $\mathrm{R} 16$ \\
17 & Aditiya Mahesa & $\mathrm{R} 17$ \\
18 & Kevin Yoga Pratama & $\mathrm{R} 18$ \\
19 & Mayang Karmila Sari & $\mathrm{R} 19$ \\
20 & Anggar Ranawijaya & $\mathrm{R} 20$ \\
21 & Alvin & $\mathrm{R} 21$ \\
22 & Ilham Fadhilah Akbar & $\mathrm{R} 22$
\end{tabular}

Journal of DINDA (Data Science, Information Technology, and Data Analytics) Vol. 1 No. 2 (2021) $63-72$ 


\section{Rudolf Dekha Silaen ${ }^{1}$, Apri Junaidi ${ }^{2}$, Ely Purnawati ${ }^{3}$ \\ Journal of DINDA (Data Science, Information Technology, and Data Analytics) \\ Vol. 1 No. 2 (2021) $63-72$}

\begin{tabular}{|c|c|c|}
\hline 23 & Nur Azizah Wulandari & R23 \\
\hline 24 & Hanif Luthfi & $\mathrm{R} 24$ \\
\hline 25 & Elsa Sri Mulyani & R25 \\
\hline 26 & Desitafs & R26 \\
\hline 27 & Gata Aulia S & R27 \\
\hline 28 & Bachtiar Gilang Ramadhan & R28 \\
\hline 29 & Katerina & R29 \\
\hline 30 & Ivon Fadhila Rahma & R30 \\
\hline 31 & Raja Surbakti & R31 \\
\hline 32 & Anggyta H Rusyadi & R32 \\
\hline 33 & Windi Yulia Andriani & R33 \\
\hline \multicolumn{3}{|c|}{ Tabel 2. Daftar Isi Kuesioner } \\
\hline No. & & Kode \\
\hline \multicolumn{3}{|c|}{ Learnability } \\
\hline 1 & Aplikasi mudah dipelajari dan digunakan & L1 \\
\hline 2 & $\begin{array}{l}\text { Informasi mengenai pengenalan budaya } \\
\text { diterima dan dimengerti }\end{array}$ & $\mathrm{L} 2$ \\
\hline 3 & $\begin{array}{l}\text { Penggunaan suara dalam informasi alat } \\
\text { musik dapat membantu memahami } \\
\text { informasi mengenai alat musik }\end{array}$ & L3 \\
\hline \multicolumn{3}{|c|}{ Efficiency } \\
\hline 1 & $\begin{array}{l}\text { Tidak membutuhkan waktu yang lama } \\
\text { untuk mengetahui informasi lengkap } \\
\text { objek }\end{array}$ & E1 \\
\hline 2 & $\begin{array}{l}\text { Tidak membutuhkan waktu yang lama } \\
\text { untuk memahami fungsi objek di rumah } \\
\text { Joglo }\end{array}$ & E2 \\
\hline \multicolumn{3}{|c|}{ Memorability } \\
\hline 1 & $\begin{array}{l}\text { Fungsi berbagai objek pada aplikasi } \\
\text { mudah diingat }\end{array}$ & M1 \\
\hline \multicolumn{3}{|c|}{ Errors } \\
\hline 1 & $\begin{array}{l}\text { Pengguna dapat memperbaiki kesalahan } \\
\text { yang dilakukan dengan mudah }\end{array}$ & ER1 \\
\hline \multicolumn{3}{|c|}{ Satisfaction } \\
\hline 1 & Aplikasi ini menarik dan menyenangkan & $\mathrm{S} 1$ \\
\hline 2 & $\begin{array}{l}\text { Tampilan objek yang terdapat dalam } \\
\text { aplikasi sudah baik }\end{array}$ & $\mathrm{S} 2$ \\
\hline 3 & $\begin{array}{l}\text { Aplikasi ini memberikan tambahan } \\
\text { informasi mengenai objek yang ada di } \\
\text { rumah Joglo }\end{array}$ & S3 \\
\hline
\end{tabular}

Tabel 3. Data Isi Kuesioner

\begin{tabular}{cccccccccccc}
\hline \multirow{2}{*}{ No. } & Kode & L1 & L2 & L3 & E1 & E2 & M1 & ER1 & S1 & S2 & Ser \\
\hline 1 & R1 & 9 & 9 & 8 & 9 & 9 & 10 & 9 & 9 & 10 & 9 \\
2 & R2 & 8 & 8 & 7 & 8 & 9 & 9 & 9 & 8 & 9 & ata. \\
3 & R3 & 9 & 9 & 9 & 9 & 9 & 9 & 9 & 9 & 9 & 9 \\
4 & R4 & 9 & 9 & 8 & 10 & 9 & 8 & 7 & 9 & 9 & 9 \\
5 & R5 & 7 & 8 & 7 & 7 & 6 & 7 & 8 & 7 & 6 & 7 \\
6 & R6 & 10 & 9 & 4 & 9 & 9 & 9 & 9 & 9 & 9 & 9 \\
7 & R7 & 10 & 10 & 10 & 10 & 10 & 10 & 10 & 10 & 10 & 10 \\
8 & R8 & 9 & 9 & 10 & 10 & 9 & 9 & 9 & 10 & 8 & 9 \\
9 & R9 & 8 & 8 & 8 & 8 & 8 & 9 & 8 & 8 & 9 & 8 \\
10 & R10 & 9 & 9 & 10 & 10 & 10 & 10 & 10 & 10 & 10 & 10 \\
11 & R11 & 7 & 8 & 7 & 9 & 8 & 8 & 7 & 9 & 8 & 9
\end{tabular}

Journal of DINDA (Data Science, Information Technology, and Data Analytics)

Vol. 1 No. 2 (2021) 63- 72 


\section{Kesimpulan}

Berdasarkan hasil penelitian Aplikasi Berbasis Virtual Reality untuk mendukung proses pembelajaran rumah Joglo, maka dapat disimpulkan sebagai berikut:

1. Aplikasi telah berhasil dibuat dengan menggunakan perancangan model SDLC (Software Development Life Cycle) dimana desain aplikasi dirancang dapat berulang-ulang agar dapat dikembangkan lebih baik.

2. Berdasarkan aplikasi VR "Rumah Joglo" membuat pembelajaran budaya Jawa Tengah lebih menarik dan mudah dipahami dikarenakan terdapat objek 3D pada rumah Jolgo dapat membantu responden melihat secara visual dan juga dapat mudah diingatkan.

3. Aplikasi dapat menjadi media pembelajaran alternatif dalam membantu proses pembelajaran budaya Jawa Tengah dikarenakan aplikasi ini mudah dipelajari dan mudah dimengerti.

\section{Daftar Rujukan}

[1]A. F. Pudyanto, "Pemodelan Virtual Reality One Day Service sebagai Media Informasi," Ums Etd, p. 6, 2014.

[2] A. Nugroho and B. A. Pramono, "Transformatika.," J. Transform., vol. 14, no. 2, pp. 86-91, 2017, [Online]. Available: http://journals.usm.ac.id/index. php/transformatika/article/view/442/277.

[3]A. Rohman and Y. E. Ningsih, "Pendidikan Multikultural : Penguatan Identitas Nasional Di Era Revolusi Industri 4.0," UNWAHA Jombang, vol. 1, no. September, pp. 44-50, 2018, [Online]. Available: http://ejournal.unwaha.ac.id/index.php/ snami/article/view/261.

[4]A. R. Triani, A. R. Adriyanto, and D. Faedhurrahman, "Media Promosi Bisnis Potensi Wisata Daerah Bandung Dengan Aplikasi Virtual Reality,” J. Bhs. Rupa, vol. 1, no. 2, pp. 136-146, 2018, doi: 10.31598/bahasarupa.v1i2.215.

[5]D. Abidarin Rosidi, Heri Sismoro, "PERANCANGAN DAN PEMBUATAN 3D MODELLING DENGAN TEKNIK CEL SHADING," DASI, vol. VOL. 17 N0, no. 1, p. 93, 2016.

[6] D. Pradiptojati, F. Samop, and N. A. Sani, "Rancang Bangun Peta Virtual 3D Jurusan Teknik Informatika Institut Teknologi Sepuluh Nopember dengan Unity3D Engine," Tek. Pomits, vol. 3, no. 2, pp. 192-197, 2014.

[7] D. Sumardani, I. Midaraeni, and N. I. Sumardani, "Virtual Reality Sebagai Media Pembelajaran
Relativitas Khusus Berbasis Google Cardboard Pada Smartphone Android," Pros. Semin. Nas. Pendidik. KALUNI, vol. 2, pp. 309-321, 2019, doi: 10.30998/prokaluni.v2i0.80.

[8] D. W. P. A. P. N. Erri Wahyu Puspitarini, "Game Edukasi Berbasis Android Sebagai Media Pembelajaran Untuk Anak Usia Dini," J I M P - J. Inform. Merdeka Pasuruan, vol. 1, no. 1, pp. 46-58, 2016, doi: 10.37438/jimp.v1i1.7.

[9]F. Z. Adami and C. Budihartanti, "Penerapan Teknologi Augmented Reality pada Media Pembelajaran Sistem Pencernaan Berbasis Android,” Tek. Komput. AMIK BSI, vol. 2, no. 1, pp. 122-131, 2016.

[10]F. Ardiyansyah, "Implementasi Pattern Recognition Pada Pengenalan Monumen-Monumen Bersejarah Di Kota Bandung Teknik Informatika Universitas Komputer Indonesia Jurnal Ilmiah Komputer Dan Informatika ( Komputa ), J J. KOMPUTA, vol. 01, 2014, doi: 10.1533/wint.2005.3441.

[11]H. M. . Nahak, "Upaya Melestarikan Budaya Indonesia Di Era Globalisasi," J. Sosiol. Nusant., vol. 5, no. 1, pp. 65-76, 2019, doi: 10.33369/jsn.5.1.65-76.

[12]I. Ruslan, "Penguatan Ketahanan Budaya Dalam Menghadapi Derasnya Arus Budaya Asing," J. TAPIs, vol. 11, no. 1, pp. 1-19, 2015.

[13]R. Triwardani, "Implementasi Kebijakan Desa Budaya Dalam Upaya Pelestarian," vol. 4, no. January 2014, pp. 102-110, 2015, [Online]. Available: https://jurnal.unitri.ac.id/index.php/ reformasi/article/view/56/53.

[14]S. Budiwibowo, "Membangun Pendidikan Karakter Generasi Muda Melalui Budaya Kearifan Lokal Di Era Global," Prem. Educ. J. Pendidik. Dasar dan Pembelajaran, vol. 3, no. 01, pp. 39-49, 2016, doi: 10.25273/pe.v3i01.57.

[15]Y. A. Paas, "Pembuatan Aplikasi Tata Ruang Tiga Dimensi Gedung Serba Guna Menggunakan Teknologi Virtual Reality [Studi," Sov. Soil Sci., vol. 18, no. 1, pp. 1-5, 2012.

[16]"07 - The Unity Game Engine - Domebase." http://www.domebase.org/4---the-unity-gameengine (accessed Aug. 05, 2020).

Journal of DINDA (Data Science, Information Technology, and Data Analytics)

Vol. 1 No. 2 (2021) $63-72$ 
[17]"blender.org - Home of the Blender project - Free [20]"Tech Explained: Virtual Reality - Springwise." and Open 3D Creation Software." https://www.springwise.com/tech-explained-virtualhttps://www.blender.org/ (accessed Aug. 05, 2020). reality/ (accessed Aug. 05, 2020).

[18]"Google lanceert testversie van Android 11 | [21]"VR Box Virtual Reality 3D Suitable for Glasses Executive People.” https://executivepeople.nl/640340/google-lanceert-testversie-vanandroid.html (accessed Aug. 05, 2020).

[19]“SketchUp Official Distributor | ACA Pacific Indonesia." https://www.acaapac.com/id/products /sketchup (accessed Aug. 05, 2020). 